\title{
A NEW NUMERICAL MODELLING APPROACH FOR FLEXIBLE ROCKFALL PROTECTION BARRIERS BASED ON FAILURE MODES
}

\author{
X. Qi ${ }^{1}$, Z.X. Yu ${ }^{2 *}$, L. Zhao ${ }^{3}$, H. Xu ${ }^{4}$ and S.C. Zhao ${ }^{5}$ \\ ${ }^{1}$ Lecturer, School of Civil Engineering, Southwest Jiaotong University, Chengdu, China \\ State Key Laboratory of Geohazard Prevention and Geoenvironment Protection, \\ Chengdu University of Technology, Chengdu, China \\ ${ }^{2}$ Associate Professor, School of Civil Engineering, Southwest Jiaotong University, Chengdu, China \\ ${ }^{3}$ Reseacher Fellow, Department of Civil and Environmental Engineering, \\ The Hong Kong Polytechnic University, Hong Kong, China \\ ${ }^{4}$ Lecturer, School of Civil Engineering, Southwest Jiaotong University, Chengdu, China \\ ${ }^{5}$ Professor, School of Civil Engineering, Southwest Jiaotong University, Chengdu, China \\ *(Corresponding author: E-mail: yzxzrq@home.swjtu.edu.cn)
}

Received: 15 August 2017; Revised: 3 September 2017; Accepted: 18 November 2017

\begin{abstract}
To study the mechanical behaviour of the flexible rockfall protection barriers under impact load, four full-scale impact tests involving protection capacities of $750 \mathrm{~kJ}$ and $2000 \mathrm{~kJ}$ were conducted, including two successful and two failed tests. The experimental results show that the system has three working stages. Among these three stages, the second and the third stages play significant roles in both absorbing the impact energy and ensuring the system performance reasonable. Based on the observed failure modes in the tests, the key factors leading to the breakdown of the system are investigated. A new numerical modelling approach is established, which is able not only to predict the capacity of the flexible protection barrier subjected to the rockfall impact but also to accurately simulate the main failure modes such as buckling of the steel post and breakage of the rope. The experimental results are employed to assess and verify the calculation model, and the numerical responses of the system are in good agreement with the test data. Furthermore, a flexible rockfall protection barrier with a capacity of $5000 \mathrm{~kJ}$ is designed by using the numerical procedure as an effective tool, shown by a full-scale impact test.
\end{abstract}

Keywords: Rockfall protection barrier, full-scale testing, finite element model, dynamic response, failure mode

DOI: $10.18057 / \mathrm{IJASC} .2018 .14 .3 .10$

\section{INTRODUCTION}

One of the most common protection measures for falling rock disasters is a flexible rockfall protection barrier, which mainly consists of a steel wire-ring net, support ropes, uphill ropes, energy dissipating devices and posts, as shown in Figure 1. In comparison to typical rigid protection structures, such as a rigid fence and an earth dam, the barrier structure consumes more impact energy owing to its flexibility, relying on the tension-compression balance among different components. Currently, flexible rockfall protection barriers have been widely used and have proved to be effective $[1,2]$. 


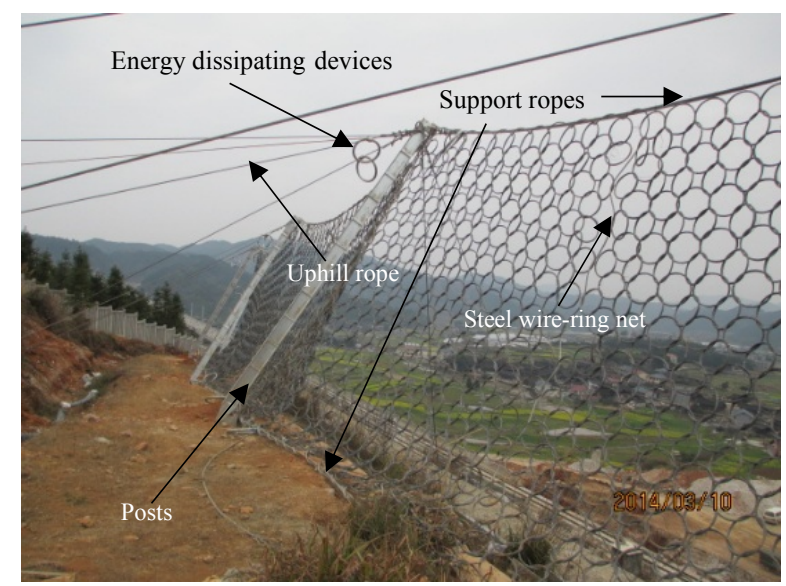

Figure 1. Composition of a Flexible Rockfall Protection Barrier

Previously, most research and experimental tests essentially focused on the static behaviour of the individual components of the protective barrier, such as interception nets and energy dissipating devices. Castro-Fresno et al. [3] studied the mechanical properties of a net with different configurations using tensile, slip and shear tests in concentrated and uniform load modes. Díaz et al. [4] investigated the energy-consuming characteristics of spring-type energy dissipator. Castanon-Jano et al. [5] summarized the composition and energy dissipating principle of the different energy dissipators used in the rockfall interception system and evaluated the energy dissipating capacity. Muhunthan et al. [6] researched the bolt forms of flexible rockfall protection barriers. Arndt et al. [7] studied the influence of the boundary constraint on the mechanical properties of the net. Without the design perspective of the structural level, the flexible protective barrier system is only a combination of those components. However, with the increased protection energy of commercial products, to date, the maximum energy level has reached $8000 \mathrm{~kJ}$, and the performance of the entire system has been considered. To determine the system parameters and verify the structural configuration, many full-scale impact tests were conducted at artificial [8] and natural $[9,10]$ rockfall test sites, so the entire impact process and protection capacity were intuitively observed. In Guideline for European Technical Approval of Falling Rock Protection Kits (ETAG 27) [11], the flexible rockfall protection barrier was, for the first time, regarded as an integrated structure rather than assembled components, which means that the loading mechanism and the failure mode should be treated as an internal interaction in the structural design. Moreover, the full-scale impact test, in addition to devices for recording the experimental data, became obligatory for final safety verification as well as more expensive. Yu et al. $[12,13]$ proposed a simple analytical method for fast evaluation of the performance of the flexible rockfall barrier system and established the equation for prediction of large deformation of flexible rockfall barrier system. Xu et al. [14] proposed an energy allocation based design approach for quickly determining the specification, size and amount of components of a flexible rockfall protection barrier structure, which based on a reliable numerical modelling validated by several experimental tests that include both component tests and full-scale impact tests.

To save costs, numerical models were developed to improve the design efficiency as well as avoid the risk of failing on-site impact tests. To propose the design method of protective barriers, the relationship between the key parameters, such as impact elongation, braking time, energy dissipation and internal forces, were obtained based on finite element [15] and discrete element [16] approaches, and the model was verified by comparison with the test results. Gentilini et al. $[9,17,18]$ equated the ring into a quadrilateral and a triangle, ignoring the bending of the net unit, modelled the components in the system by truss elements, and established an overall 3D calculation model of flexible rockfall protection barriers. Escallón et al. [19] established the calculation units of the 
interception net based on a reverse formula and genetic algorithm. Although the existing models are able to simulate the entire impact process of flexible protection barriers, most models only present good working performance for successful interception. In other words, few of models involve failure simulation or failure pattern prediction, so the effective guidance for the design and optimization of the structure cannot be provided.

In this paper, two failed full-scale impact tests that involve protection capacities of $750 \mathrm{~kJ}$ and 2000 $\mathrm{kJ}$ as well as two corresponding successful tests are presented. Three working stages of the system during the successful interception impact process are defined, and the damage mechanism of the structure is analysed. Then, a numerical approach that can predict the failure modes, verified by the experimental results, is developed for design of the barrier structural design. The details of the full-scale tests are introduced in Section 2, as well as the description of the failure mechanism and mode of the flexible protection barriers. The methods of modelling each component and boundary constraints in the numerical simulation are shown in Section 3. In Section 4, the comparison between the test and the simulation results are employed to validate the proposed numerical model. Finally, a high-performance flexible rockfall barrier with a capacity of $5000 \mathrm{~kJ}$ is designed by numerical procedure, and both the experimental and the predicted results are presented in Section 5.

\section{FULL-SCALED ROCKFALL TEST}

\subsection{Test Set Up}

The rockfall impact test shown in Figure 2 refers to the representative standard ETAG 27. The test site, located in Xinjin County (Sichuan, China) includes the reaction wall, the cantilever crane and the testing equipment.



Figure 2. Overall View of the Test Site

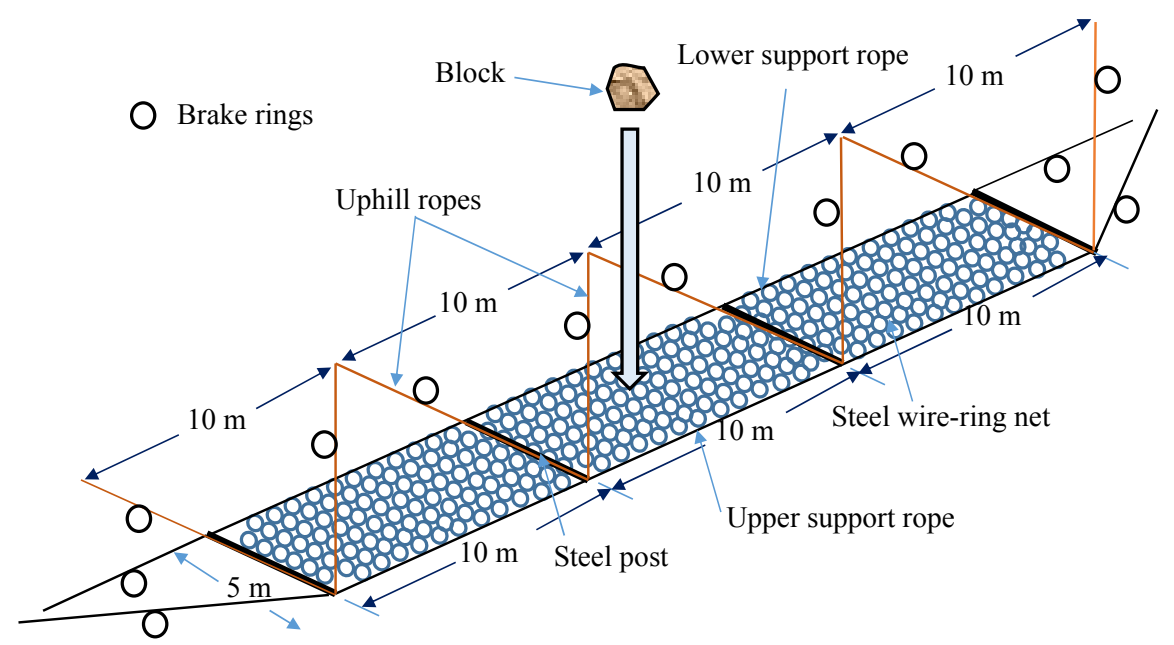

Figure 3. Test System Composition

To study the failure modes of the barrier system, two failed experiments (RXI-750-1 and RXI-2000-1) are selected, and after some improvements, the corresponding successful experiments (RXI-750-2 and RXI-2000-2) are also presented. Furthermore, a 5000 kJ impact test was carried out to verify the correctness of the proposed numerical approach in prediction and design.

The layout of the test models is shown in Figure 3. Each test model has three functional modules 
and four steel posts with a height of $5 \mathrm{~m}$. The horizontal spacing between the posts is $10 \mathrm{~m}$. The post feet are fixed on the $\mathrm{RC}$ reaction wall by a pin hinge that provides rotational freedom in the vertical plane, and the post caps are connected to the uphill rope. All of the posts and the net are set horizontally, subjected to the impact load of a free-falling block. A high-speed camera is used to record the entire impact process, as well as the deformation of the brake rings. Load cells with a frequency of $10000 \mathrm{~Hz}$ are used to measure the tensile force of uphill ropes and support ropes.

Table 1. Main Parameters of the Experimental Models

\begin{tabular}{|c|c|c|c|c|c|}
\hline & RXI-750-1 & RXI-750-2 & RXI-2000-1 & RXI-2000-2 & RXI-5000 \\
\hline Steel wire-ring net & $\mathrm{R} 7 / 3 / 300$ & $\mathrm{R} 7 / 3 / 300$ & $\mathrm{R} 12 / 3 / 300$ & $\mathrm{R} 12 / 3 / 300$ & $\mathrm{R} 19 / 3 / 300$ \\
\hline Uphill ropes & $1 \Phi 16$ & $1 \Phi 16$ & $1 \Phi 22$ & $2 \Phi 22$ & $2 \Phi 22$ \\
\hline Support ropes & $2 \Phi 18$ & $2 \Phi 18$ & $2 \Phi 18$ & $2 \Phi 22$ & $2 \Phi 24$ \\
\hline 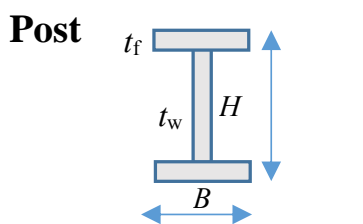 & $\begin{array}{l}H=200 \mathrm{~mm} \\
B=100 \mathrm{~mm} \\
t_{\mathrm{w}}=7 \mathrm{~mm} \\
t_{\mathrm{f}}=11 \mathrm{~mm}\end{array}$ & $\begin{array}{l}H=175 \mathrm{~mm} \\
B \quad=175 \\
\mathrm{~mm} \\
t_{\mathrm{w}}=7 \mathrm{~mm} \\
t_{\mathrm{f}}=11 \mathrm{~mm}\end{array}$ & $\begin{array}{l}H=200 \mathrm{~mm} \\
B=200 \mathrm{~mm} \\
t_{\mathrm{w}}=8 \mathrm{~mm} \\
t_{\mathrm{f}}=12 \mathrm{~mm}\end{array}$ & $\begin{array}{l}H=200 \mathrm{~mm} \\
B=200 \mathrm{~mm} \\
t_{\mathrm{w}}=8 \mathrm{~mm} \\
t_{\mathrm{f}}=12 \mathrm{~mm}\end{array}$ & $\begin{array}{l}H=300 \mathrm{~mm} \\
B=300 \mathrm{~mm} \\
t_{\mathrm{w}}=10 \mathrm{~mm} \\
t_{\mathrm{f}}=15\end{array}$ \\
\hline $\begin{array}{l}\text { Number of brake } \\
\text { rings in support } \\
\text { rope }\end{array}$ & 24 & - $2 x=2 x$ & 22 & 22 & 32 \\
\hline $\begin{array}{l}\text { Number of brake } \\
\text { rings in uphill ropes }\end{array}$ & 16 & 16 & 32 & 24 & 72 \\
\hline Block(mass/height) & $5 \mathrm{t} / 15 \mathrm{~m}$ & $5 \mathrm{t} / 15 \mathrm{~m}$ & $6.5 \mathrm{t} / 32 \mathrm{~m}$ & $6.5 \mathrm{t} / 32 \mathrm{~m}$ & $15.6 \mathrm{t} / 32 \mathrm{~m}$ \\
\hline Results & Failed & Successful & Failed & Successful & Successful \\
\hline Note & $\begin{array}{l}\text { Steel posts } \\
\text { bulked }\end{array}$ & & $\begin{array}{l}\text { Upper } \\
\text { support rope } \\
\text { broke } \\
\end{array}$ & & \\
\hline
\end{tabular}

The configuration details are given in Table 1. It can be seen that as the protection capacity grows, the component sizes and amount of brake rings become larger, while all the brake rings used in the test are GS-8002 type [20]. With respect to RXI-750-1, the steel posts with wider flanges are adopted in RXI-750-2, and the difference between RXI-2000-1 and RXI-2000-2 is the number of brake rings on the uphill ropes.

\section{$2.2 \quad$ Three-Stage Mechanical Behaviour}

According to the full-scale impact test results recorded by the high-speed camera and the load cells, the braking time of the block lasts $0.25 \sim 0.5 \mathrm{~s}$, which is mainly related to the system configuration. As the braking time increases, the impact force decreases. By analysing the high-speed photography, it is found that the impact force and deformation of the system are characterized by similar three-stage behaviour in the two successful tests (RXI-750-2, RXI-2000-2), revealing an entire working mechanism of the intercepting process (Figure 4).

In the first stage, the initial equilibrium state of the system, in which the barrier structure is only subjected to its own gravity, is converted into the tight state, as shown in Figure 4a. The deformation of the system in this stage that mainly caused by bending deformation of steel wire-rings and slipping of the net along the support ropes. This accounts for $30-40 \%$ of the total impact elongation, while most of the material in the system remains within the elastic state. Until the end of this stage, all the break rings have not yet been activated. 
In the second stage, as the elongation of the system along the impact direction increases, the tensile forces of the support ropes become greater, leading to activations of most of the dissipators on the support ropes. With the shrinkage towards the middle module, the steel wire-ring net slides along the support ropes, forming a funnel shape as illustrated in Figure $4 \mathrm{~b}$. During this process, the energy dissipated by the system mainly consists of the sliding friction work and the plastic deformation of the brake rings.

In the third stage, an additional elongation of the system is supplied by the activation of the dissipator on the uphill ropes, as shown in Figure 4c. Then, the block continues to move downwards, even as the strokes of the brake rings are moved, until the maximum elongation is reached, when the total kinetic energy of the block has transferred into the internal energy of the barrier structure completely. At the end of this stage, the impact area of the wire-ring net has significant plastic deformations, including plastic bending and stretching. In addition, with respect to the original position, both middle posts swing down, and the displacements depend on the elongations of the brake rings on the uphill ropes.

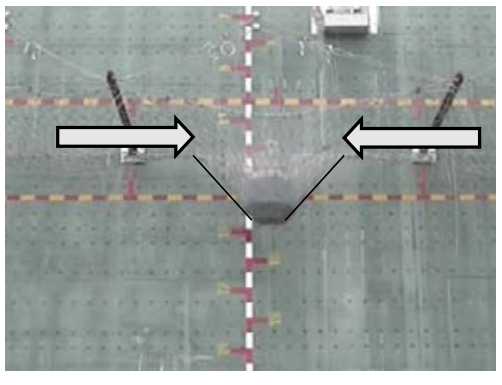

(a) First stage

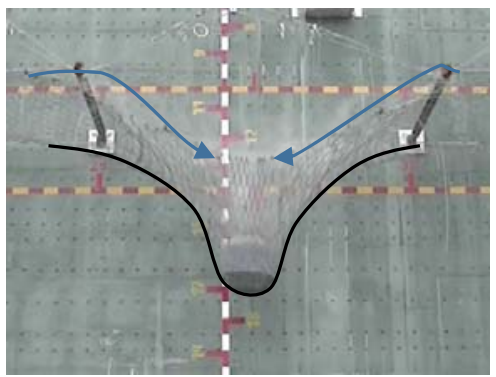

(b) Second stage

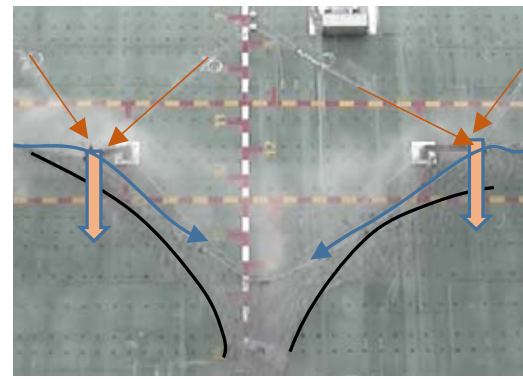

(c) Third stage

Figure 4. Deformation Characteristics of the Barrier Structure at Three Different Stages

\subsection{Damage Mechanism and Failure Modes of the System}

In the two failed experiments, buckling of the posts occurred in the model RXI-750-1, and the upper support rope broke in model RXI-2000-1. Using high-speed photography, it can be seen that both tests present a complete first stage; however, the force transferring characteristics of different experimental models are very discrepant in the second and third stages.

The model RXI-750-1 was damaged at the end of stage 2. From Figure 5a, C-type semi-wavy buckling of the steel posts occurred before it should have rotated around the horizontal axis of the fixed end in the vertical plane. The model RXI-750-2 showed the complete three-stage mechanical behaviour, while the brake rings on the support and uphill ropes fully worked. The system remained intact after the test, as shown in Figure $5 \mathrm{~b}$.

At the end of the second stage, the brake rings on the support ropes in model RXI-2000-1 were stretched relatively completely. Since the brake rings on the uphill ropes were not activated due to the overlarge activation force, the system could not enter into the third stage, resulting in breakage of the support ropes and destruction of the system, as shown in Figure 5c. As seen from Figure 5d, with respect to model RXI-2000-1, the less number of brake rings led to an adequate activation force, enabling the system to enter into the third stage. Then, the dissipators on both of the support ropes and the uphill ropes ran the full stroke to intercept the block successfully, indicating the satisfying integral working performance of the barrier system. 


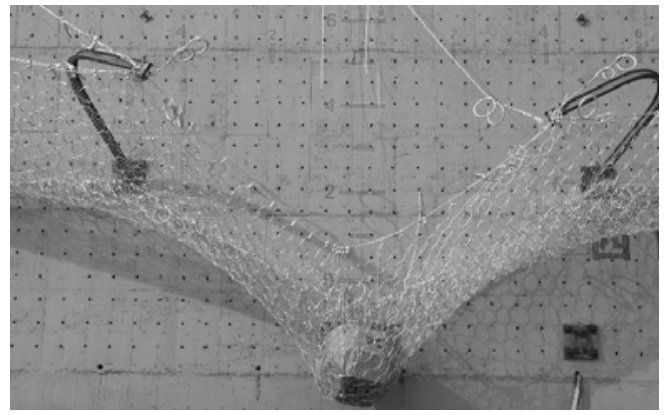

(a) RXI-750-1

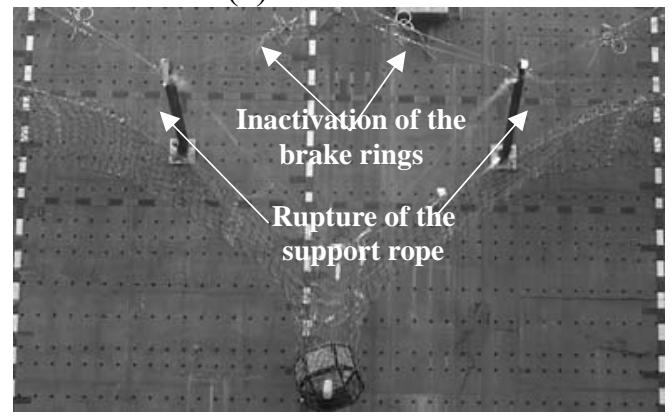

(c) RXI-2000-1

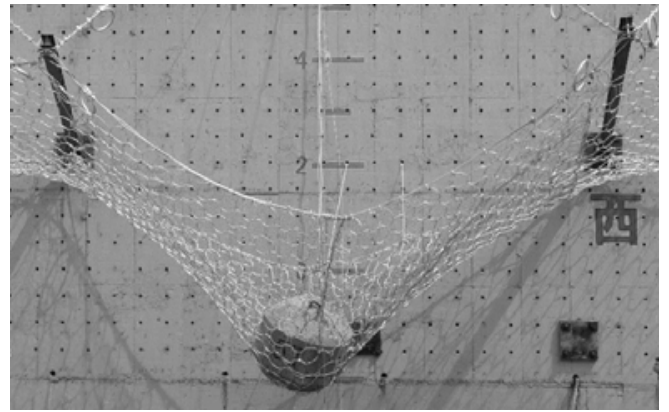

(b) RXI-750-2

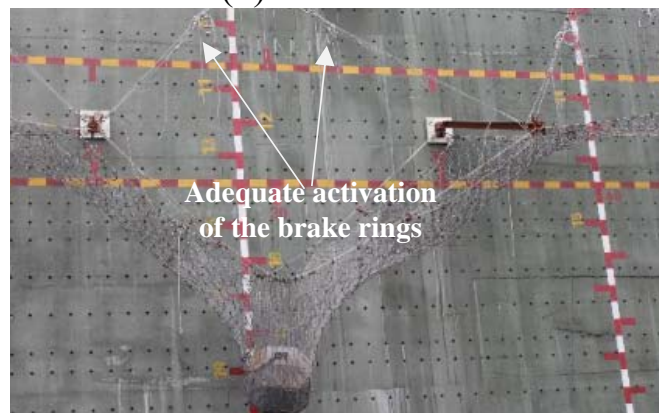

(d) RXI-2000-2

Figure 5. Test Results of Different Configurations for Model RXI-750 and RXI-2000

According to the analysis of the force transferring characteristics of the system, the elongations of the upper and lower support ropes greatly influence the deformability of the barrier structure. In particular, the upper support rope plays a very important role in activating the second and the third stages, since the post caps were directly connected with the uphill ropes to support it.

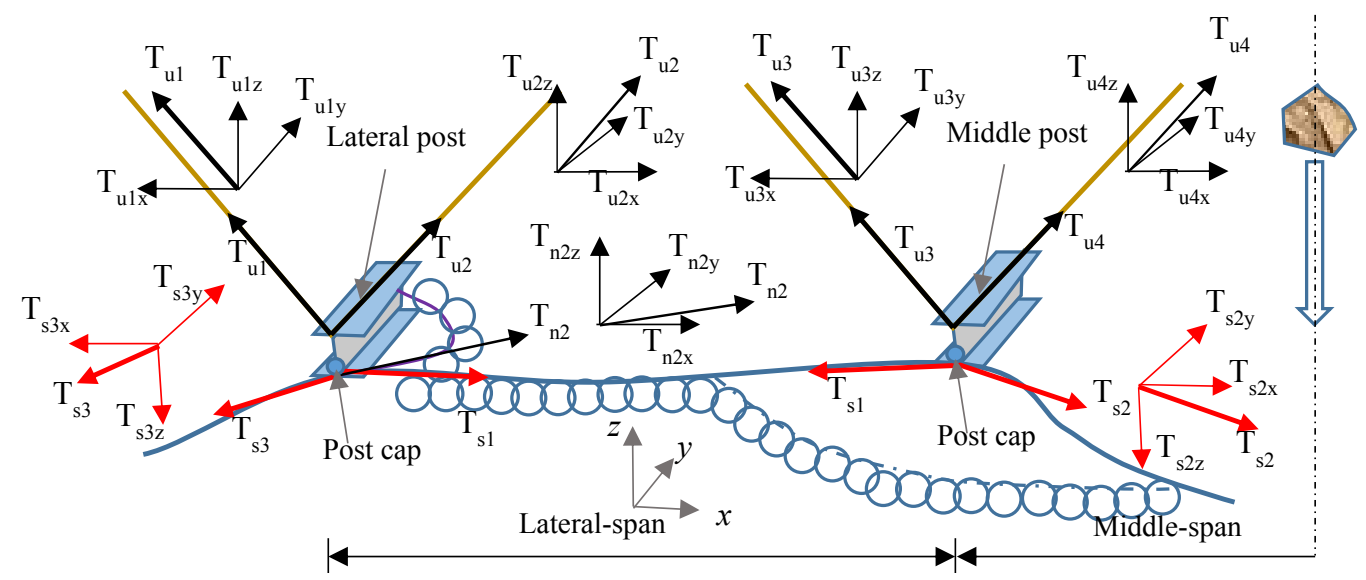

Figure 6. Force Transferring Mechanism among the Upper Support Rope, the Post Caps and the Uphill Ropes

Figure 6 depicts the internal forces of the upper support rope and the uphill ropes as well as their three components in the global coordinate system. The tensile forces of the upper support ropes in the lateral-span and middle-span are $T_{\mathrm{s} 1}$ and $T_{\mathrm{s} 2}$, respectively. In the second stage, when the upper support rope slides towards the middle span, each post cap subjected to loadings from the upper support rope and the uphill ropes tends to swing to the opposite direction along which the support 
rope slides. Simultaneously, the vertical component $T_{\mathrm{s} 2 \mathrm{z}}$ of the upper support rope in the middle-span, acting on the post cap, is totally borne by the uphill ropes. As the elongation of the system increases at this stage, the impact force between the block and the wire-ring net keeps increasing, and the internal forces of the upper support rope and the vertical load $T_{\mathrm{s} 2 \mathrm{z}}$ act on the post caps. Once the tensile force of the uphill ropes reaches a threshold equal to the activation force of the dissipators, the posts will swing down depending on the elongations of the brake ring on the uphill ropes, signifying that the system enters into the third stage.

The planar hinges at the post feet enable the posts to rotate freely in the vertical plane. While in the horizontal plane, the rotation is restricted finitely, which means that the posts can swing towards both lateral sides freely within a small range, as depicted in Figure. 7. Hence, in the first stage and the majority of the second stage, the posts are only subjected to axial loading due to the boundary conditions and the small magnitude of the interaction forces between the post caps and the support ropes. However, once the rotation of the post in the vertical plane is beyond the limitation, an additional bending moment will act on the post suddenly so that the uniaxial compression state of the post will be converted to the compound loading state that includes uniaxial compression and a bending moment about the weak axis. The post is prone to buckling damage as the load increases, similar to the failure mode of model RXI-750-1.

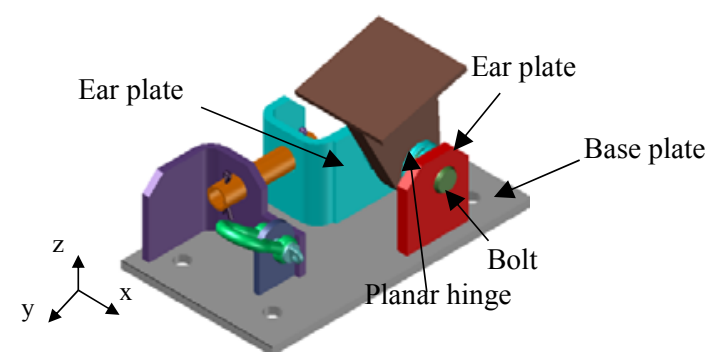

Figure 7. Configuration of the Base Plate of the Post

Therefore, in the third stage, a large portion of the kinetic energy of the block is consumed in terms of plastic strain energy and sliding friction of the dissipators on the uphill ropes. On the other hand, if the brake rings on the uphill ropes are not activated, the kinetic energy needs to be dissipated by the increasing impact force acting along the direction of deformation of the system. Thus, the tensile forces of the support ropes and the wire-ring net continue to increase so that the support ropes and the net would be broken. Hence, the activation of the dissipators on the uphill ropes relieves, to some extent, the burden of the high tensile forces of the support ropes and the wire net. The posts continue to be subjected to uniaxial loading without large transverse forces, avoiding buckling damage. Although it is shown from the experiments that the working states of the upper and lower support ropes are similar to each other, due to the different spatial locations related to the posts, the demand of elongation for the lower support ropes is greater than that for the upper support ropes, resulting in fuller strokes of the dissipators on the lower support rope. Meanwhile, the tensile force of the lower support ropes is also greater than that of the upper ropes.

Accordingly, failure modes of the flexible barrier structure can be generally classified as the following three types:

1) Collapse of the system caused by the buckling failure of the steel posts, in most cases featured by C-type semi-wavy buckling

2) Breakage of the uphill ropes and support ropes

3) Breakage of the steel wire-ring net 


\section{NUMERICAL SIMULATION APPROACH}

According to the working process and potential failure modes studied from the tests, difficulties caused by highly nonlinear problems must be overcome for simulating the dynamic response of the flexible barrier structure. To establish an accurate numerical method, except the impact contact relationship and the elastoplastic material properties, various other key features should also be considered. These include the large deformation of the net, the sliding relationships among the components, the constraints of the steel post feet, the conversion process from axial pressure instability to bending instability of the steel posts, and the failure criteria of the components. Then, a three-dimensional finite element model that can predict the impact results and failure modes is developed and presented to provide effective guidance for optimizing and designing the flexible barrier structure.

\subsection{Main Bearing Components}

1) The wire-ring net is modelled as an interlocking collection of rings, and each ring connects to four other rings using the automatic contact algorithm (Figure 8a). Each ring is composed of super-strength steel wires with a diameter of $3 \mathrm{~mm}$ and yield strength of $1.770 \mathrm{GPa}$. The beam element and a piecewise elastoplastic material model is used, while the behaviour of the elements is described by both the cross-sectional area and the uniaxial stress-strain relationship (Figure 8b). $\sigma$ and $\varepsilon$ represent the effective stress and effective strain, respectively. According to the material test results, $\sigma_{1}=1.2 \mathrm{GPa}, \sigma_{2}=1.77 \mathrm{GPa}, \varepsilon_{1}=0.002$ and $\varepsilon_{2}=0.05$.

2) It is difficult to accurately simulate the geometrical non-linearity that particularly refers to the sliding behaviour between the net and the ropes. In this paper, the segments of the support ropes that can slide along the post caps are modelled by means of the sliding cable elements (Figure 8c), which act as pulley systems. Each sliding cable element contains three dominant nodes, which are node 1, node 2 and node 3, as depicted in Fig. 8d. The intermediate node (node 1) coincides with the post end node, and the sliding distance of the support rope depends on the location of the two lateral points (node 2 and node 3). Even though the spatial positions of the support ropes change during the impact process of the system, the positive distance $\left(\Delta_{1-2}\right)$ along the axial direction of the sliding cable element is always equal to the negative distance $\left(\Delta_{1-s}\right)$ to coordinate the elongation of the support ropes. However, a friction coefficient equal to 0.15 is set between the support rope and the post cap so that the tensile force of the support rope is also influenced by the sliding friction as the rope slides along the post cap. Sufficient length, mainly relying on the maximum stroke of the dissipators, should be reserved for the sliding cable element in case the sliding distance is beyond the length of the sliding cable element. The final positions of the dominant points of the sliding cable element (node 1,2 and 3) are determined by the rotation of the posts and the extension of the break rings, since the coordinates of node 1 are always duplicated with that of the post ends.

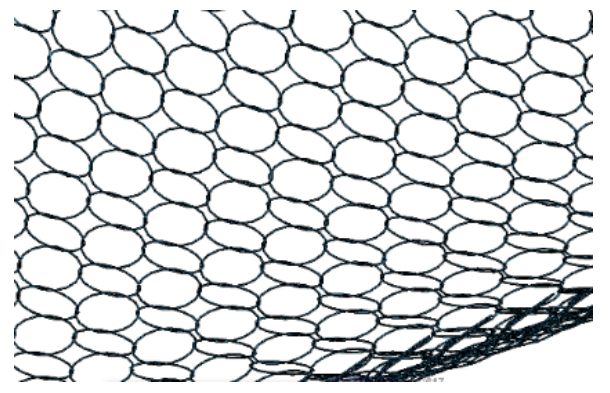

(a) Wire-ring net

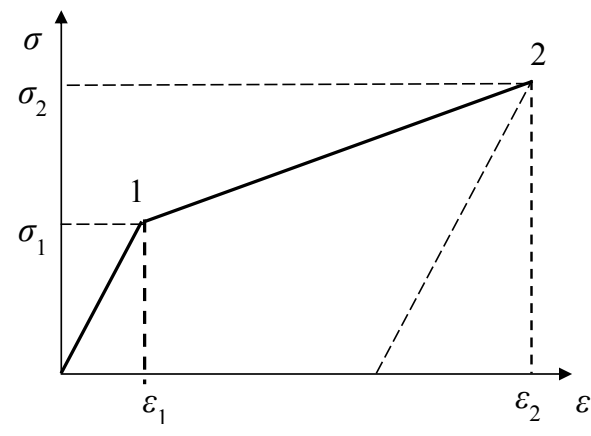

(b) Constitutive laws for steel of the wire-ring 


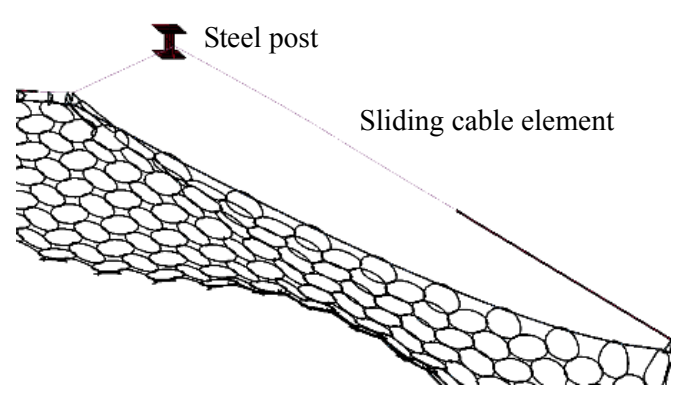

(c) Sliding cable element

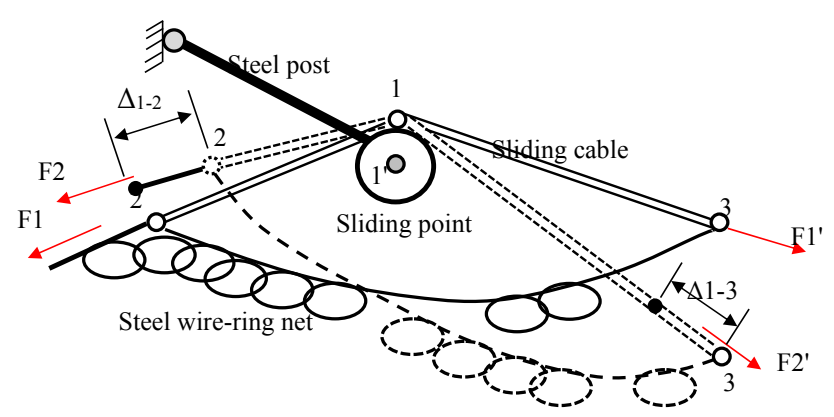

(d) Dominant points of the sliding cable element

Figure 8. Elements Adopted for the Wire-ring Net and Sliding Segments of the Support Ropes

3) Nonlinear springs are employed in this paper as dissipators. Based on a group of quasi-static brake rings tests (Figure 9a), the force-displacement relationship is defined, and the key parameters are determined, as shown in Figure $9 \mathrm{~b} . F_{1}$ represents the activation force of the brake ring. $L$ represents the maximum elongation of the brake ring, $L \approx \pi \mathrm{d}$. $L_{\mathrm{e}}$ denotes the breakout elongation of the brake ring, and according to the test results (Figure 9) and statistical analysis, $L_{e} \approx L / 50 . L_{1}$ is the simplified sliding length of the brake ring; $L 1 \approx L / 5, L_{2} \approx 4 L / 5$, and $k_{1} \approx F_{1} / L_{1} \approx \mu_{\mathrm{s}} F_{\mathrm{n}} / L_{1}$, and $\mu_{\mathrm{s}}$ is the friction factor between the preload sleeve and the brake ring.

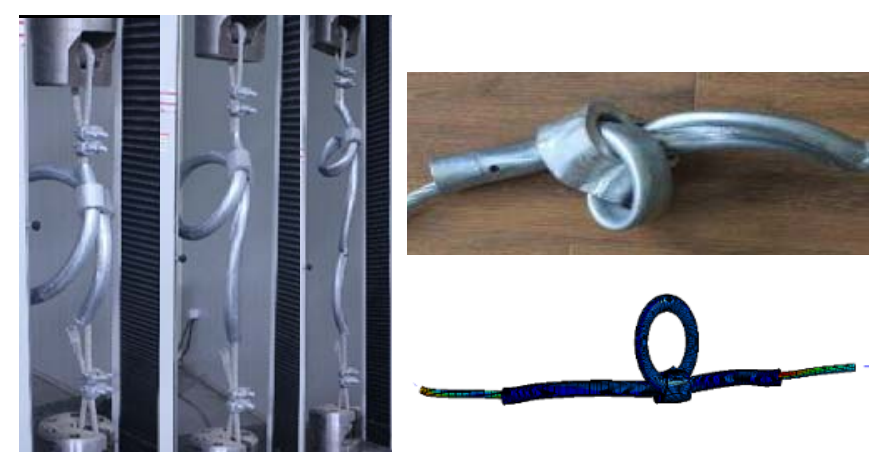

(a) Quasi-static tests

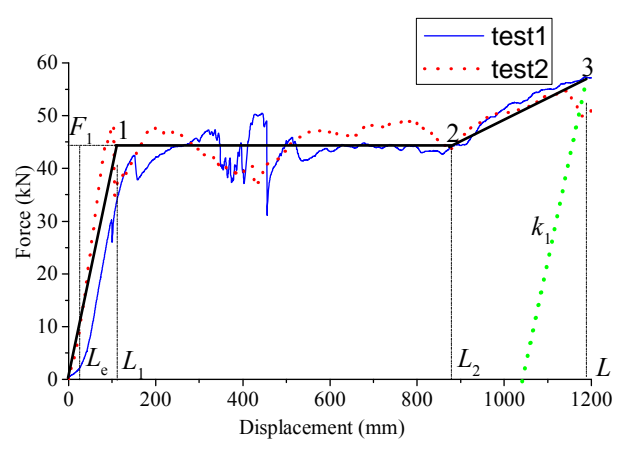

(b) Force-displacement of the brake ring

Figure 9. Numerical Model of the Brake Rings Based on Experimental Tests

\subsection{Boundary Constraints}

The automatic contact technique governed by the symmetric penalty function method is applied to the numerical model. In particular, a dynamic friction coefficient equal to 0.2 is set between the block and the wire-ring net, among the wire-rings. As depicted in Figure 10a, the support rope is connected to the wire-ring net via shackles, which are modelled as rigid elements. The guided-cable relationship [18] is employed between the shackles and the support rope so the shackles can slide along the rope during the impact process.

An ideal hinge joint is used at the post foot for free rotation in the vertical plane, while a nonlinear rotational spring is set for behaviour of the post in the horizontal plane. The relationship between bending moment $M$ and rotational angle $\theta$ is illustrated in Figure $10 \mathrm{~b}$, in which $\theta_{1}=15^{\circ}$ and $k_{1}=\min \left\{k_{\theta \mathrm{c}}, k_{\theta \mathrm{p}}\right\} . k_{\theta \mathrm{c}}$ and $k_{\theta \mathrm{p}}$ are the bending stiffness of the posts and pin hinge lugs, respectively, in the horizontal plane. $k_{\theta \mathrm{c}}$ is determined by the actual cross-section dimensions of the post, $k_{\theta \mathrm{p}}$ depends on the configuration of the post foot, mainly influenced by the dimensions of the pin and the pin-hole, as well as the distance between the ear plates (Figure 7), and the value can be obtained by the numerical simulation from a 3D FE model. 


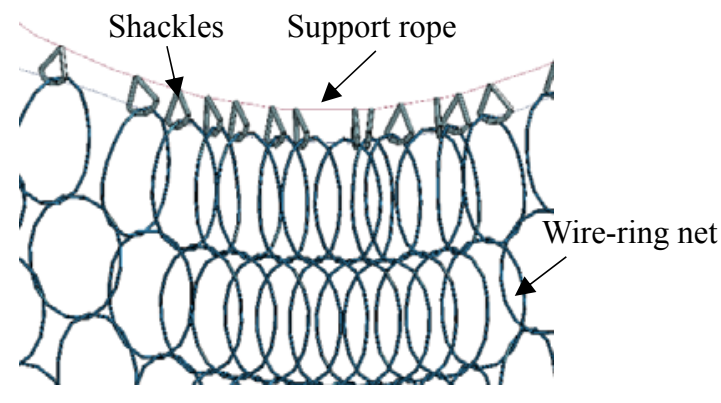

(a) Net to rope connection



(b) Model of rotation-limited constraint

Figure 10. Typical Boundary Conditions

\subsection{Dynamic Algorithm Method}

An explicit dynamic algorithm is employed to calculate the entire collision process between the block and the net. To ensure the accuracy of the simulation, the scale factor for the Rayleigh time-step is set to 0.9 . For lightening the computational burden, the block is initially positioned above the wire-ring net with a small gap, and an initial velocity is defined according to the impact energy level. The calculation is terminated at the end of the first rebound after impact. Furthermore, the stress of the model is initialized only under the gravity before impact. It is noted that, to preliminarily assess the results, the balance among the global internal energy, kinetic energy and hourglass energy must be taken into account to verify the stability of the energy state of the entire system.

\section{ANALYSIS OF THE CALCULATION RESULTS}

Based on the aforementioned numerical approaches, 4 models were simulated using the commercial LS-DYNA software program (notations referred to in Section 2).

The numerical simulations reproduced the features observed in each working stage of the tests, including the sliding of the support ropes, the deformation of the brake rings, the rotation of steel posts, and the similar failure modes.

For the test model RXI-750-1, a system collapse occurred, as seen in Figures 11a and 11b. There are two reasons leading to this failure mode. First, the brake rings mounted on the longitudinal upper support ropes between the lateral post and the middle post were jammed at the post cap along which the ropes were sliding, resulting in the increase of lateral force and bending moment of the posts. Second, under great axial compression, it is much easier for damage to occur about the weak axis plane of the post with an H-type cross section than about the strong axis plane. Compared with model RXI-750-1, wider flange plates were adopted in model RXI-750-2. Through calculation, even if the brake rings are jammed at the post caps, requirements can be met by the increased bending stiffness about the weak axis plane of the post. Therefore, the result of model RX-750-2 was consistent with the expectation that the abovementioned failure mode is avoided, as seen in Figures $11 \mathrm{c}$ and $11 \mathrm{~d}$.

With regard to model RXI-2000-1, considering the impact energy is large enough, to ensure the support ropes slide smoothly through the post caps, all the brake rings on the support ropes were mounted symmetrically at both outer sides of the lateral posts rather than between the posts. 
However, the upper support rope in model RXI-2000-1 was broken during the test, as depicted in Figure 11e. These results occur because the third working stage explained in Figure 4c was not activated, so the great impact of the internal forces was unexpectedly borne in the net and the support ropes. This impact mainly occurred because the four brake rings are mounted on each uphill rope in terms of a parallel connection, leading to an excessively large activation force. As shown in Figure 11f, the numerical simulation also represented the phenomenon that the activation force of the brake rings on the uphill ropes is too large, so they fail to participate in the system work. Therefore, in model RXI-2000-2, only two brake rings are mounted on each uphill rope, as illustrated in Figures $11 \mathrm{~g}$ and $11 \mathrm{~h}$. The final result shows that the improved system has successfully intercepted the rock without damage.

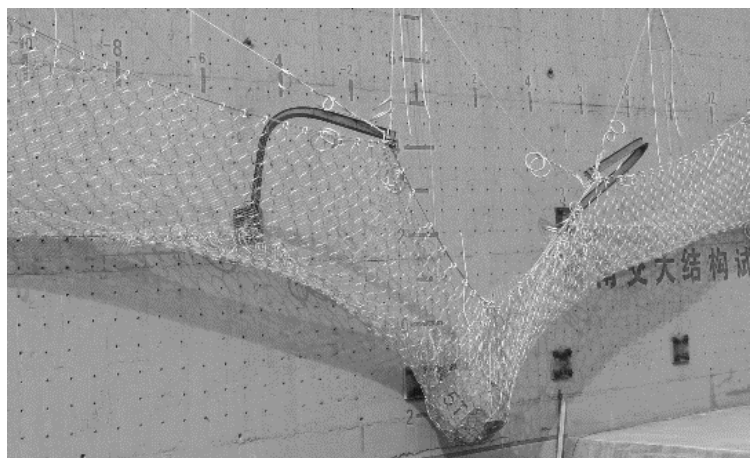

(a) Test result of model RXI-750-1

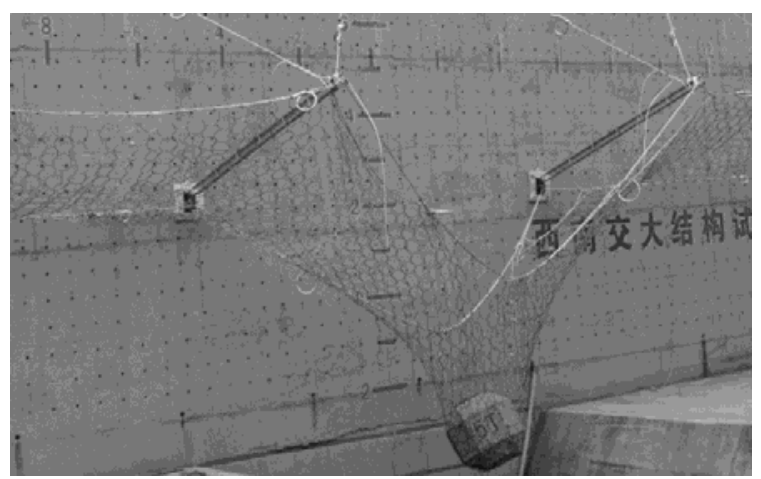

(c) Test result of model RXI-750-2

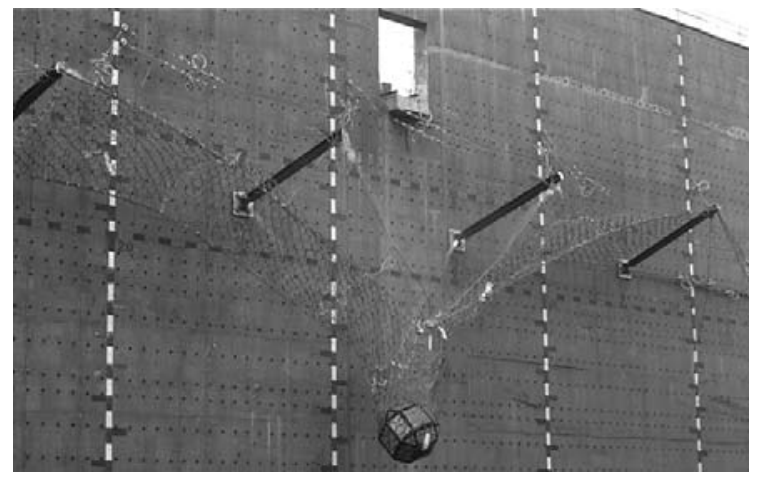

(e) Test result of model RXI-2000-1

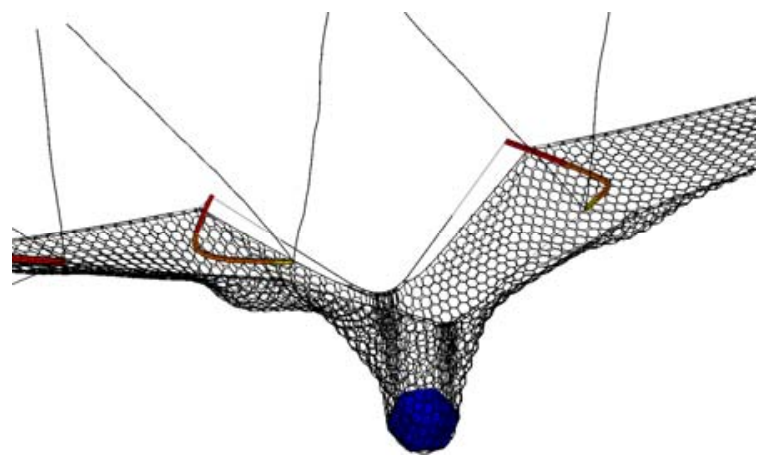

(b) Simulation result of RXI-750-1



(d) Simulation result of RXI-750-2

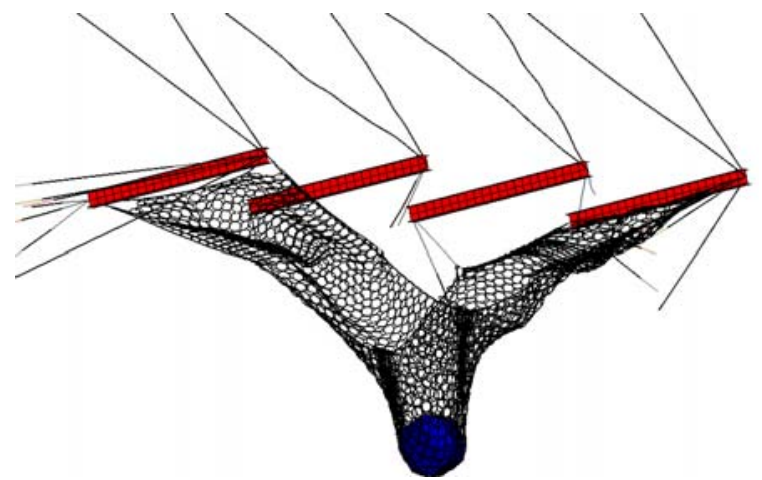

(f) Simulation result of RXI-2000-1 


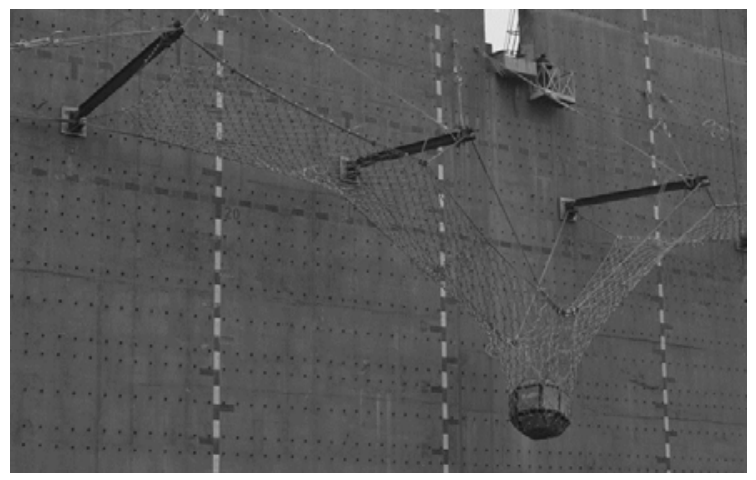

(g) Test result of model RXI-2000-2

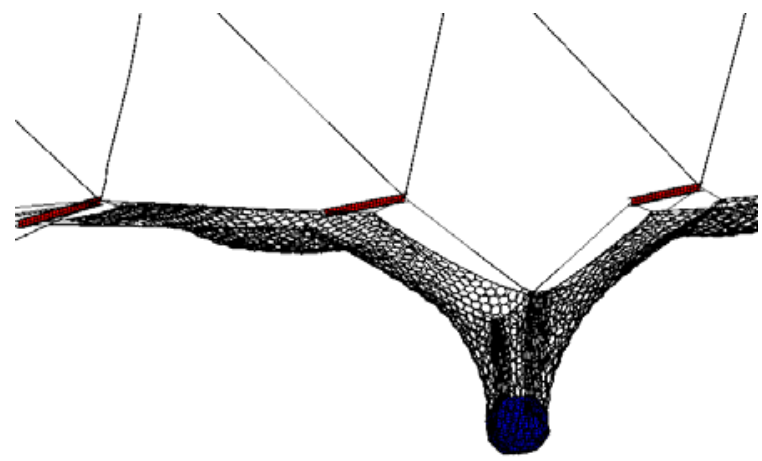

(h) Simulation result of RXI-2000-2

Figure 11. Experimental Results and Numerical Simulation Results

The tensile forces in different ropes of model RXI-750-2 and RXI-2000-2 from tests and simulations are given in Figure 12, which shows coincidences between experimental and numerical time-history curves. Also from Figure 12 it is clear that the tensile force of the support rope is obviously greater than that of the uphill rope.

Figure 13 plots the time-history curves of impact forces from the simulations, which captures the main features of the test data. In particular, the mechanical behaviour characterized by three different stages can be reflected in the numerical results. According to the European guidelines [11] some key indexes of the deformation, such as the elongation along the impact direction and the residual height after the test (the minimum distance between the lower and the upper rope), are very important parameters to evaluate the barrier performance. As given in Table 2, the maximum deviation of the vertical elongation and the residual protective height between tests and simulations are $5 \%$ and $16 \%$, respectively. Such deviation can be caused by many reasons, of which the most important include the slightly eccentric impact in the tests, measurement errors, as well as the inevitable differences between the experimental and numerical models, such as the complicated connecting measures modelled by the simplified joints or elements.

Table 2. Comparison of Key Deformation Indexes between Tests and Simulations

\begin{tabular}{ccccc}
\hline & \multicolumn{2}{c}{ Models } & Results (m) & Deviation \\
\hline \multirow{2}{*}{$\begin{array}{c}\text { Vertical maximum impact } \\
\text { deformation }\end{array}$} & RXI-750-2 & Test & 5.6 & $4 \%$ \\
& Simulation & 5.8 & \\
& RXI-2000-2 & Test & 7.0 & $5 \%$ \\
& Simulation & 7.36 & \\
& RXI-750-2 & Test & 2.4 & $16 \%$ \\
Residual height after the test & Simulation & 2.8 & \\
& RXI-2000-2 & Test & 3.4 & $5 \%$ \\
\hline
\end{tabular}



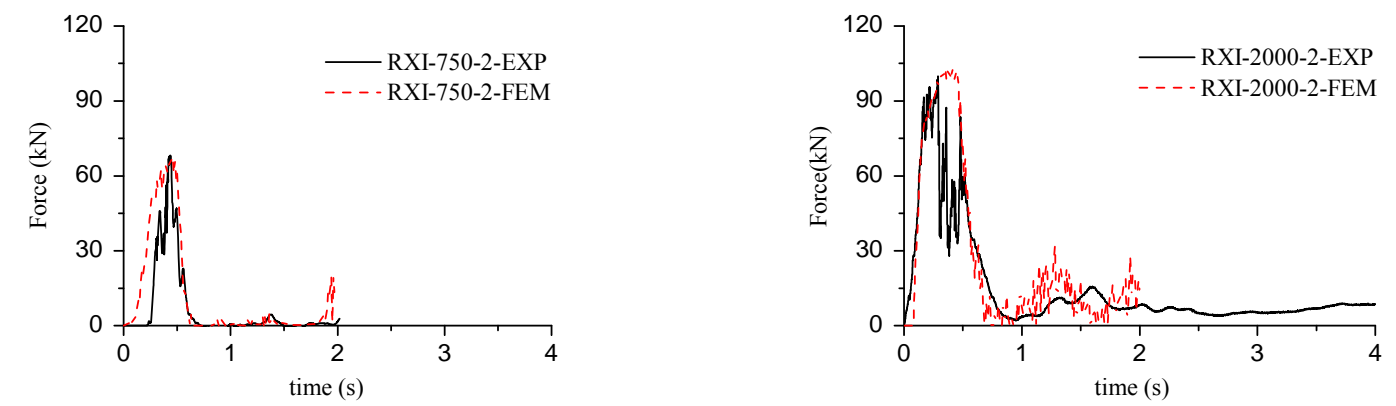

(a) Lower Support Ropes
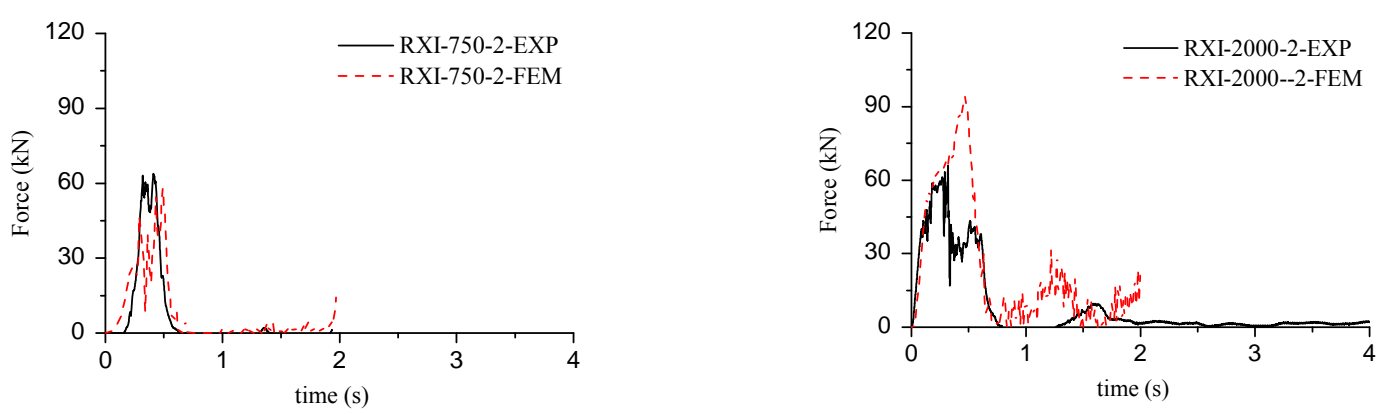

(b) Upper Support Ropes
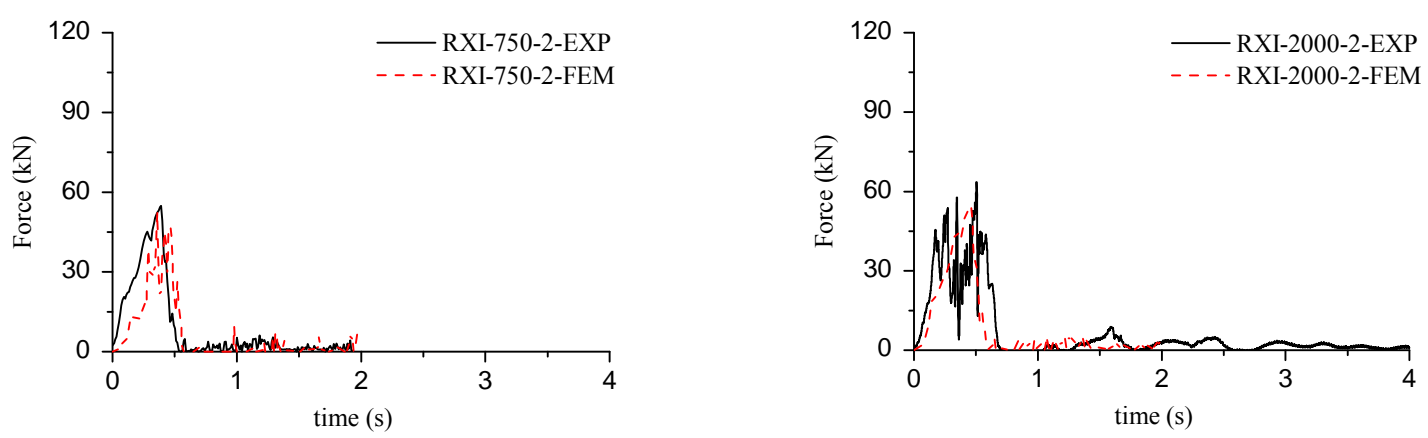

(c) Uphill Ropes

Figure 12. Time-history Curves of Tensile Forces

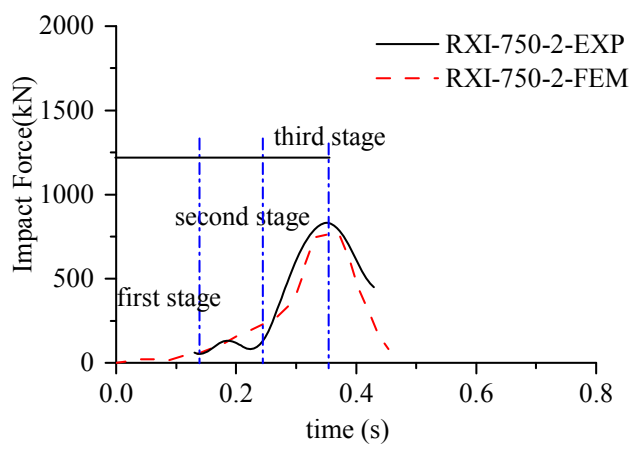

(a) RXI-750-2

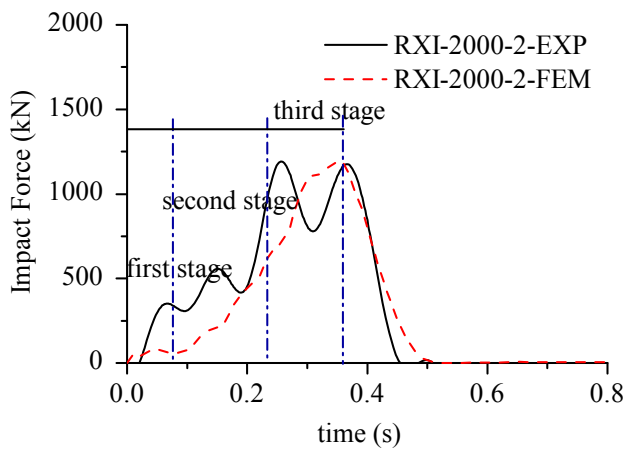

(b) RXI-2000-2

Figure 13. Comparison of the Time-history Curves of the Impact Forces between Experimental and Numerical results for models 


\section{UTILIZATION OF THE MODEL FOR DESIGN}

Based on the above numerical strategy, a new type of high-performance flexible protective barrier was constructed. The main parameters of components in the system are shown in Table 1. Verified by the design procedure based on the numerical simulation, model RXI-5000 can successfully intercept the block with impact energy of $5000 \mathrm{~kJ}$. According to the impact process simulation, the wire-ring net was immediately thrust downward at the beginning of impact, leading to the elongation of the support ropes owing to the activation of the brake rings mounted on the support ropes. The interaction between the posts and the support ropes grew when the support ropes slipped along the posts. Then, the steel posts transferred the forces to the uphill ropes, and the brake rings on the uphill rope were activated, which supplied displacement for the steel posts. The simulation result indicated that all components of the barrier, especially the wire-ring net, and the brake rings on the support ropes and uphill ropes worked fully during the entire impact process.

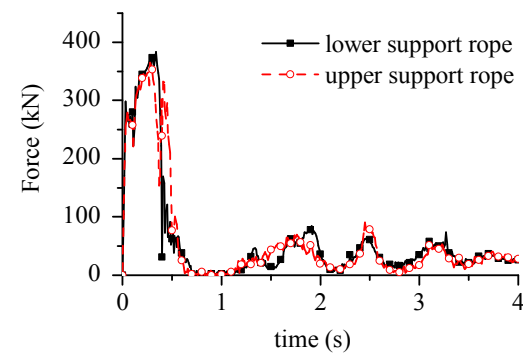

(a) Upper and Lower Support Rope

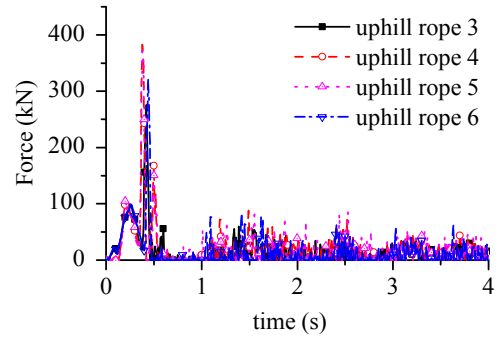

(b) Uphill Ropes Connected to the Middle Posts

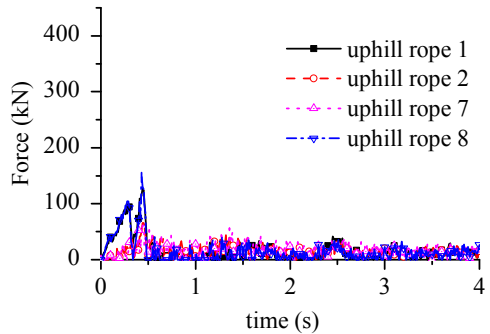

(c) Uphill Ropes Connected to the Lateral Posts

Figure 14. Tensile Forces of Ropes of model RXI-5000

After checking the internal forces of each component to guarantee the necessary safety reserve coefficients, a full-scale test of RXI-5000 was conducted. In particular, the tensile forces in the ropes of model RXI-5000 from the numerical simulation are obtained, as shown in Figure 14. The peak forces of the upper and lower support ropes shown in Fig. 14a are much greater than those of models RXI-750 and RXI-2000. The greatest peak force of the uphill ropes connected to the middle posts (Fig. 14b) is as large as the force of the support ropes that nearly reaches $400 \mathrm{kN}$. Relatively, the peak forces of the uphill ropes connected to the lateral posts are much lower, as depicted in Fig. $14 \mathrm{c}$.

Figure 15 depicts the comparison of the impact process of model RXI-500 between the test (the first column) and the numerical simulation (the second column), including the moments of initial contact $(\mathrm{t}=0.05 \mathrm{~s})$, the sway of the steel posts $(\mathrm{t}=0.22 \mathrm{~s})$, the maximum displacement during impact $(\mathrm{t}=0.44 \mathrm{~s})$, and the final state after the first rebound $(\mathrm{t}=0.60 \mathrm{~s})$. The results show that the numerical simulation of the entire process is in a good agreement with the test results. Furthermore, the time-history curves of the impact force and the displacement of the block predicted via the simulation are compared with the test results in Figure 16. The good match between the simulation and the test results indicates that the new system has the capacity for protecting against the block with an impact energy of $5000 \mathrm{~kJ}$ and again proves the three-stage behaviour for successful rock interception. 

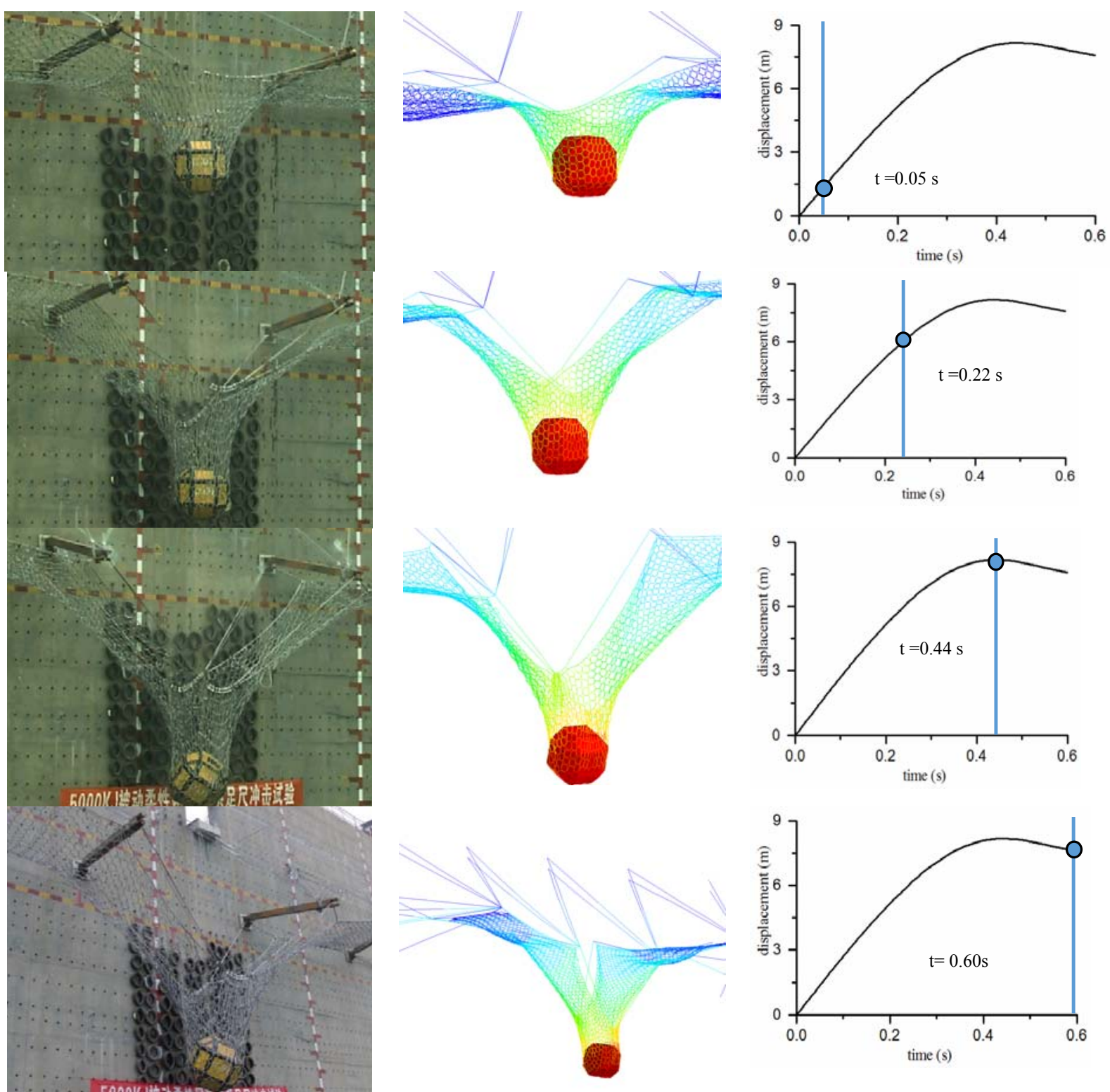

Figure 15. Test Result and Simulation Prediction of the Entire Impact Process of Model RXI-5000



(a) Impact Force

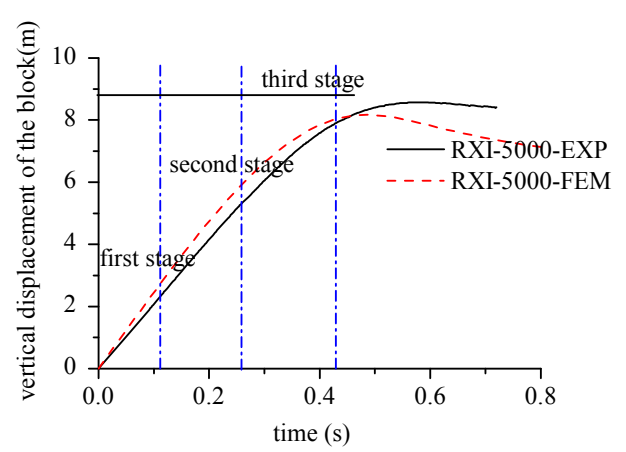

(b) Vertical Displacement of the Block

Figure 16. Comparison of Time-history Curves between Simulation and Test 


\section{CONCLUSIONS}

1) According to two groups of full-scale tests, the load-transferring mechanism and failure modes of the flexible rockfall protective barrier are revealed. An effective and successful interception of the flexible rockfall protective barrier structure consists of three mechanical stages, which are classified with key moments when the specific components are loaded or activated. Hence, the protection capacity of the structure is determined not only by the capacity of each component but also by the rational assortment and allocation of each part, which can realize the three-stage behaviour.

2) A numerical approach for the flexible barrier structure is presented, which has been validated by comparison with the experimental results. The proposed simulation method can reappear in the three-stage mechanical behaviour, as well as be reproduced in the different failure modes in the actual structures. Therefore, the numerical model can be used as an efficient tool for design and optimization, owing to its good performance in predicting the response of the barrier structure under impact loads.

3) A high-performance flexible barrier structure with protection capacity of $5000 \mathrm{~kJ}$ has been numerically designed and experimentally tested. The sufficient safety reserve coefficients are necessary in the design. Furthermore, to enable each part of the system to work fully and for actions to transfer smoothly among all components, these are the most essential issues to be addressed.

\section{ACKNOWLEDGMENT}

The work of this study was supported by the National Natural Science Foundation of China [Grant No. 51408498, 51678504], Department of Science and Technology of Sichuan Province [Grant No. 2018JY0029], the foundation of State Key Laboratory of Geohazard Prevention and Geoenvironment Protection [Grant No. SKLGP2016K013] and the Fundamental Research Funds for the Central Universities [Grant No. 2682017CX006].

\section{REFERENCES}

[1] Gottardi, G., Govoni, L. and Mentani, A., "The Effectiveness of Protection Systems Toward Rockfall Risk Mitigation”, 2011 Bundesanstalt für Wasserbau. Vogt, Schuppener, Straub \& Bräu, 2011, pp. 157-164.

[2] Has, B., Hanaoka, M., Nozawa, E., Momose, A. and Sasaki, K., "Behavior and Mechanism of Earthquake-Induced Landslides within Pre-Existing Landslide Topography: the Case of the 2004 Mid-Niigata Prefecture Earthquake, Japan”, Disaster Mitigation of Debris Flows, Slope Failures and Landslides, Japan, Interpraeven, 2006, pp. 35-46.

[3] Castro-Fresno, D., Diaz, J.J.D.C., López, L.A. and Nieto, P.J.G., "Evaluation of the Resistant Capacity of Cable Nets using the Finite Element Method and Experimental Validation”, Engineering Geology, 2008, Vol. 100, No. 1, pp. 1-10.

[4] Díaz, J.J.D.C., Nieto, P.J.G., Castro-Fresno, D. and Rodríguez-Hernández, J., "Nonlinear Explicit Analysis and Study of the Behaviour of a New Ring-type Brake Energy Dissipator by FEM and Experimental Comparison”, Applied Mathematics and Computation, 2010, Vol. 216, No. 5, pp. 1571-1582. 
[5] Castanon-Jano, L., Blanco-Fernandez, E., Castro-Fresno, D. and Ballester-Muñoz, F., "Energy Dissipating Devices in Falling Rock Protection Barriers", Rock Mechanics and Rock Engineering, 2016, Vol. 50, No. 3, pp. 603-619.

[6] Muhunthan, B. and Radhakrishnan H., "Finite Element Analysis of Hybrid Barrier for Rock Fall Slope Protection", Final Report, Department of Civil and Environmental Engineering, Washington State University, 2007.

[7] Arndt, B., Ortiz, T. and Turner, A.K., "Colorado's Full-Scale Field Testing of Rockfall Attenuator Systems", Transportation Research E-Circular, 2009.

[8] Peila, D., Pelizza, S. and Sassudelli, F., "Evaluation of Behaviour of Rockfall Restraining Nets by Full Scale Tests”, Rock Mechanics \& Rock Engineering, 1998, Vol. 31, No. 1, pp.1-24.

[9] Gentilini, C., Govoni, L., Miranda, S.D., Gottardi, G. and Ubertini, F., "Three-dimensional Numerical Modelling of Falling Rock Protection Barriers”, Computers and Geotechnics, 2012, Vol. 44, No. 44, pp. 58-72.

[10] Gottardi, G. and Govoni, L., "Full-scale Modelling of Falling Rock Protection Barriers", Rock Mechanics and Rock Engineering, 2010, Vol. 43, No. 3, pp. 261-274.

[11] European Organisation for Technical Approvals, "Guideline for European Technical Approval of Falling Rock Protection Kits (ETAG 027)", Brussels, February, 2012.

[12] Yu Z.X., Qiao Y.K., Zhao L., et.al. A simple analytical method for evaluation of flexible rockfall barrier part 1: working mechanism and analytical solution [J]. Advanced Steel Construction, 2018, Vol. 14, No. , pp. 115-141.

[13] Yu Z.X., Qiao Y.K., Zhao L., et.al. A simple analytical method for evaluation of flexible rockfall barrier part 2: application and full-scale test [J]. Advanced Steel Construction, 2018, Vol. 14, No., pp. 142-165.

[14] Xu H., Gentilini G., Yu Z.X., et.al. An energy allocation based design approach for flexible rockfall protection barriers[J]. Engineering Structures. 2018, Vol. 173, pp. 831-852.

[15] Grassl, H., Bartelt, P., Ammann, W.J. and Roth, A., "Behavior, Design and Reliability of Highly Flexible Rockfall Protection Systems for Highways", Proc. 53rd Highway Geology Symposium, California, 2002.

[16] Nicot, F., Cambou B. and Mazzoleni G., "Design of Rockfall Restraining Nets from a Discrete Element Modelling”, Rock Mechanics and Rock Engineering, 2001, Vol. 34, No. 2, pp. 99-118.

[17] Gentilini, C., Ubertini, F., Govoni, L., Gottardi, G. and Miranda, S.D., "Modelling of Falling Rock Protection Barriers", International Journal of Physical Modelling in Geotechnics, 2011, Vol. 11, No. 4, pp. 126-137.

[18] Gentilini, C., Gottardi, G., Govoni, L., Mentani, A. and Ubertini, F., "Design of Falling Rock Protection Barriers using Numerical Models", Engineering Structures, 2013, Vol. 50, No. 3, pp. 96-106.

[19] Escallón, J.P., Wendeler, C., Chatzi, E. and Bartelt, P., "Parameter Identification of Rockfall Protection Barrier Components through an Inverse Formulation", Engineering Structures, 2014, Vol. 77, pp. 1-16.

[20] TB/T 3089-2004, "The Flexible Safety Net for Protection of Slope along the Line", China Railway Publishing House, Beijing, 2004. ( in Chinese ) 